Marquette University

e-Publications@Marquette

History Faculty Research and Publications

History, Department of

$1-1-2001$

\title{
Pallavicino, Pietro Sforza
}

John P. Donnelly

Marquette University, john.p.donnelly@marquette.edu

Published version. "Pallavicino, Pietro Sforza," Diccionario Historico de la Compania de Jesus:

Biografico-Tematico. Eds. Charles E. O'Neill and Joaquín M. a Domínguez. Madrid: Universidad

Pontificia Comillas, 2001: 2958. Publisher Link. (C) 2001 Universidad Pontificia Comillas. Used with permission. 
Pallavicino (PAllavicini), Pietro Sforza. Historiador, teólogo, cardenal.

N. 28 noviembre 1607, Roma, Italia; m. 5 junio 1667, Roma.

E. 21 junio 1637, Roma; o. 1630, probablemente Roma; ú.v. 2 febrero 1641, Roma.

Hijo mayor de la rama de Parma de la noble familia de los Pallavicini, renunció a la herencia paterna para seguir la carrera clerical. Estudió literatura, filosofía y teología en el *Colegio Romano, donde obtuvo los doctorados en filosofía (1625) y teología (1628). Cursó, además, estudios de derecho en la Sapienza. Su origen noble y talento innegable hicieron que $P$ ascendiese en el servicio de la curia pontificia, pero en 1632 incurrió en el enojo de Urbano VIII, quien le mandó a gobernar varias ciudades montañosas de poca importancia en el centro de Italia (Iesi, Orvieto y Camerino), lejos de los círculos literarios de Roma, donde era ya famoso como poeta, tanto en latín como en italiano. Contra los deseos de su familia, entró en la CJ y enseñó (1639-1642) filosofía en el Colegio Romano. En 1644 sucedió en la cátedra de teología a Juan de *Lugo, creado cardenal, y siguió su docencia hasta 1652 .

En 1651, Inocencio X le había encargado refutar la obra antirromana del servita Paolo Sarpi, Istoria del Concilio Tridentino. P continuó la labor de Terenzio *Alciati, quien por veinticinco años había recogido copioso material, pero que la muerte le impidió terminar. La gran obra en dos volúmenes de $\mathrm{P}$, Istoria del Concilio di Trento (1656-1657) no tiene la brillantez y penetración de la de Sarpi, pero está mejor documentada. Ambas manifiestan fuertes prejuicios en direcciones opuestas, y sólo la reciente de Hubert Jedin las ha sustituido. En 1655, Fabio Chigi, el amigo más íntimo de $\mathrm{P}$ desde su juventud, fue elegido papa como Alejandro VII. Éste, que con frecuencia le consultaba, le creó cardenal in pectore el 9 abril 1657, y lo hizo público el 10 noviembre 1659. P comenzó una biografía del Papa, pero tuvo que dejarla sin terminar, ya que el trabajo en varias congregaciones y, en especial, la del Santo Oficio, requerían todo su tiempo. Al caer enfermo en abril 1667, se trasladó al noviciado de Sant'Andrea al Quirinale y murió dos semanas después que el Papa. Fue sepultado en la iglesia del noviciado.

Su producción literaria fue vasta y variada. Escribió sobre el estilo literario y compuso una tragedia Ermenegildo martire (1644), que se estrenó en el Colegio Romano. Sus Vindicationes Societatis Iesu responden, a petición del P. General Vicente Carafa, a las acusaciones contra la CJ del ex jesuita Giulio Clemente *Scotti. Sus obras teológicas, que deben mucho a su amigo Lugo, revelan más erudición que originalidad. Entre éstas, las mejores fueron Assertiones theologicae y Disputationes in primam secundae D. Thomae; sobre filosofía moral, De Bene (1644), y en espiritualidad, Arte della perfezione Cristiana (1665), que se hizo muy popular, gracias a su estilo atractivo. Su secretario, Giambattista Paravelli, publicó una colección de sus cartas en 1668.
OBRAS: Considerazione sopra l'arte dello stile (Roma, 1646). Vindicationes Societatis Iesu... (Roma, 1649). Assertiones theologicae $8 \mathrm{v}$. (Roma, 1649-1652). Disputationes in primam secundae D. Thomae (Lyón, 1653). Istoria del Concilio di Trento 2 v. (Roma, 1656-1657). Lettere dettate dal Card. Sforza Pallavicino di gloriosa memoria, ed. G. Galli Pavarelli (Roma, 1668). Della vita di Alessandro VII 2 v. (Prato, 1839-1840). Pensieri e profili, ed. M. Ziino (Nápoles, 1927).

\section{FUENTES: ARSI: Opp. NN. 270-278.}

BIBLIOGRAFÍA: AfFo, I., Vita del Cardinal Sforza Pallavicino (Roma, 1845). Asor RosA, A., La cultura della Controriforma (Bari, 1974) 126-136. BBKL 6:1464-1466. Costanzo, M., «Note sulla poetica del Pallavicino», Giornale Storico della Letteratura Italiana 86 (1959) 517-555. Croce, F., "Sforza Pallavicino", Tre momenti del barocco letterario italiano (Florencia, 1966) 161-220. JEDIN, H., Der Quellenapparat der Konzilsgeschichte Pallavicinos. Das Papsttum und die Widerlegung Sarpis im Lichte neuerschlossener Archivalien (Roma, 1940). ÍD., Das Konzil von Trient: Ein Überblick über die Erforschung seiner Geschichte (Roma, 1949) 95-118. Косн 1362-1363. МассHIA, I., Relazioni fra il padre gesuita Sforza Pallavicino con Fabio Chigi (Pontefice Alessandro VII) (Turín, 1907). Pallavicino Mossi, L., Sforza Pallavicino (1607-1667) (Bolonia, 1933). Petronio, G., Dizionario enciclopedico della letteratura italiana 5 v. (Bari, 1966-1968) 4:225-226. Polgár 3/2:615-617. RaImond, E., Trattatisti e narratori del Seicento (Nápoles, 1960) 191-262. SANTos, Obispados, 1:164-169. SOMMERVOGEL 6:120-143. Verbo 14:1155. DTC 11:1831-1834. EC 9:643-646. EF 4:1294-1295. EI 26:125-126. LTK 8:6-7. NCE 10:928.

J. P. DONNELLY 